\title{
The Use of Sleep Medication in Youth Residential Care
}

\author{
Beate Oerbeck, PhD, Kristin Romvig Overgaard, MD, PhD, ${ }^{1}$ Vidar Hjellvik, $\mathrm{PhD}$, \\ Jørgen G. Bramness, MD, PhD, ${ }^{3,4}$ Berit Hjelde Hansen, MD, $\mathrm{PhD}, 5$ and Lars Lien, MD, $\mathrm{PhD}^{3,6}$
}

\begin{abstract}
Objectives: To investigate the use of sleep medication and concomitant psychotropic medication in children and adolescents placed under residential care (RC).

Methods: Participants were youth 0-20 years of age placed in RC institutions at least once during 2016. Data on filled prescriptions were taken from the Norwegian Prescription Database to compare the use of sleep medication in RC with the general child population (GenPop) and how it covaried with gender, age, reasons for RC placement, and concomitant use of other psychotropic medications (antidepressants, anxiolytics, antipsychotics, and psychostimulants).

Results: A total of 2171 youths were identified in RC at mean age 14 years ( $82 \% \geq 13$ years). Seventeen percent (371/2171) used sleep medications (melatonin $11 \%$, alimemazine $7 \%$, and benzodiazepines/z-hypnotics $2 \%$ ) significantly more than the $2.3 \%$ who used in GenPop. The girl/boy ratio for medication use in $\mathrm{RC}$ was 1.8 (95\% confidence interval $[\mathrm{CI}]=1.5-2.2)$, not significantly different from the corresponding ratio in GenPop $(1.4 ; 95 \% \mathrm{CI}=1.3-1.5)$. The use of sleep medication increased with age. When comparing reasons for placement in $\mathrm{RC}$, medication use was particularly low among unaccompanied minor asylum seekers (2\%). About half of the youths used concomitant psychotropic medication, with clear gender differences; girls used about twice as much antidepressants, anxiolytics, and antipsychotics, whereas boys used 1.3 times more psychostimulants.

Conclusion: Youths in RC used more sleep medication and concomitant psychotropic medication than the GenPop, most likely reflecting the increased psychosocial strain and mental disorders reported in this population. Further studies of prevalence, assessment, and treatment of sleep problems in RC populations are warranted.
\end{abstract}

Keywords: residential youth care, sleep medication, hypnotics, antipsychotics, psychostimulants, antidepressants

\section{Introduction}

C HILDREN AND ADOLESCENTS are placed under residential care (RC) because of severe psychosocial strain, maltreatment, and/or serious behavioral problems or being unaccompanied minor asylum seekers. All these placement reasons represent risk factors for mental disorders (Fazel et al. 2005; Green et al. 2010), and high rates of psychiatric and/or neurodevelopmental disorders were indeed reported in an early study of youths across five sectors of care (Garland et al. 2001) and later corroborated in a national U.S. sample (Turney and Wildeman 2016). Similar high rates were confirmed in a large British study, but in that study, a significantly higher prevalence was found among children in RC compared with those in foster care (71\% vs. 39\%, respectively) (Ford et al. 2007). The British findings were replicated in Norway, where $76 \%$ of youths in RC were reported to have any psychiatric disorder (Jozefiak et al. 2016) and 52\% among those in foster care (Lehmann et al. 2013).

Sleep problems are common in childhood and particularly prevalent in children with psychiatric and/or neurodevelopmental disorders (Alfano and Gamble 2009; Baddam et al. 2018; Maski and Owens 2018). The interaction between sleep and psychopathology is complex, with significant interrelationships found in the

\footnotetext{
${ }^{1}$ Division of Mental Health and Addiction, Oslo University Hospital, Oslo, Norway.

${ }^{2}$ Department of Chronic Diseases and Ageing, Norwegian Institute of Public Health, Oslo, Norway.

${ }^{3}$ Norwegian National Advisory Unit on Concurrent Substance Abuse and Mental Health Disorders, Innlandet Hospital Trust, Hamar, Norway.

${ }^{4}$ Department of Alcohol, Tobacco and Drugs, Norwegian Institute of Public Health, Oslo, Norway.

${ }^{5}$ Department of Rare Disorders and Disabilities, Oslo University Hospital, Oslo, Norway.

${ }^{6}$ Faculty of Health and Social Science, Inland University College of Applied Science, Elverum, Norway.

Funding: This study had no specific funding and was carried out as part of the authors' clinical positions.
}

(c) Beate Oerbeck et al. 2020; Published by Mary Ann Liebert, Inc. This Open Access article is distributed under the terms of the Creative Commons Attribution Noncommercial License (http://creativecommons.org/licenses/by-nc/4.0/) which permits any noncommercial use, distribution, and reproduction in any medium, provided the original author(s) and the source are cited. 
development, severity, and prognosis of psychiatric disorders and their comorbid sleep disturbances (Ramtekkar and Ivanenko 2015). With regard to age and gender, studies show that although the rates of sleep problems generally show a slight preponderance among boys in younger years, girls outnumber boys from puberty onward (Johnson et al. 2006; Sivertsen et al. 2017).

Studies of sleep problems in children and adolescents in care are rare, and although studies of psychiatric disorders in youths in care have been carried out (Lehmann et al. 2013; Jozefiak et al. 2016), the prevalence of sleep disorders were not reported. However, one U.S. study found that sleep problems partially mediated the link between adverse childhood experiences and delinquency among children in foster care (Hambrick et al. 2018). Furthermore, selfreported sleep problems were found to be associated with both anxiety, attention-deficit/hyperactivity disorder (ADHD) symptoms, and sexual abuse in Canadian adolescents placed under RC (Langevin et al. 2019), thus underlining the importance of sleep problems in vulnerable populations.

Generally, nonpharmacological treatment is the first choice for sleep problems in children and adolescents, and evidence-based pharmacological guidelines are not available (Owens and Moturi 2009; Pelayo and Yuen 2012; Economou et al. 2018). This is owing to the paucity of data available with regard to dosage, efficacy, and tolerability in youths. Although solid scientific support is missing, off-label hypnotic medications are frequently used (Stojanovski et al. 2007), supposedly justified at least by their clinical effectiveness (Bruni et al. 2019). In Norway, melatonin and antihistamines were most frequently prescribed in 0 - to 17 -year-olds (Hartz et al. 2012), whereas in the United States, where melatonin is not a prescription medication, antihistamines were most frequently prescribed (Stojanovski et al. 2007; Meltzer et al. 2014). A recent review on the pharmacologic treatment for sleep disorders in children showed that melatonin significantly improved sleep latency, sleep duration, and wake time after sleep onset, but not number of awakenings per night (McDonagh et al. 2019). The medications included in that review were sedative hypnotics (not benzodiazepines), antihistamines, antidepressants (not tricyclic antidepressants), alpha-adrenergic agonists, antipsychotics, and melatonin. The authors concluded that melatonin was useful in improving some sleep outcomes in the short term, particularly when comorbid with neurodevelopmental disorders, whereas the other sleep medications were considered to be inadequately studied.

With regard to the use of psychotropic medications, differential international variations have been reported in the literature. In a study comparing 0- to 19-year-olds in three countries, the use of hypnotics was $33 \%$ in the Netherlands, $16 \%$ in the United States, and 9\% in Germany, whereas United States had the highest use of antidepressants and psychostimulants (about three times greater than the other two), and antipsychotics (about two times greater) (Zito et al. 2008a). For children in foster care, research has shown that they are far more likely than other children to receive any psychotropic medication (Kutz 2011; Rubin et al. 2012), and also several different classes of them ( $41 \%$ received $\geq 3$ different classes) (Zito et al. 2008b). Although psychiatric symptoms are considered the most salient factors related to use of psychotropic medication in youths, studies have also shown the influence of demographic characteristics (Lopez-Leon et al. 2018). No consistent relationship with gender (Warner et al. 2014), or a male preponderance (Zito et al. 2008b; Leslie et al. 2010) has been shown, with exceptions from studies focusing on the specific class of antidepressants, where girls are more likely to be medicated (Schroder et al. 2017). With regard to age, estimates of use tend to increase with age, but exceptions are re- ported; for instance, Zito et al. (2008b) reported highest medication rates between the ages of 10 and 14 years, compared with both younger and older youths in foster care.

To the best of our knowledge, studies of the use of sleep medication within child RC are lacking (for details on our systematic search in literature databases MEDLINE, EMBASE, and PsycINFO databases, see Supplementary Appendix SA1).

The aim of the study was therefore to investigate the use of sleep medication in a Norwegian cohort of youths placed in RC, including how the use of sleep medication varied with gender, age, reasons for placement in $\mathrm{RC}$, and the concomitant use of other psychotropic medication (antidepressants, anxiolytics, antipsychotics, and psychostimulants).

\section{Methods}

\section{Study population}

Participants were all children and adolescents 0-20 years of age placed in RC institutions under the Norwegian Directorate for Children, Youth and Family Affairs, Child Welfare Services (BUFDIR) at least once during 2016. This directorate is responsible for all RC institutions in Norway except for those in the municipality of Oslo, which administers its own institutions. Consequently, $80 \%$ of Norwegian RC institutions were included in this study. Available data on the participants were gender, age, and reasons for placement in $\mathrm{RC}$ institutions. Placement reasons include neglect, emergency placement, serious behavioral problems of high and low degree, substance abuse, and being unaccompanied minor asylum seekers.

\section{Prescription drug data}

For the RC population, data on all filled prescriptions during 2016 were available from the Norwegian Prescription Database (NorPD) for each individual. The drugs were classified according to the Anatomical Therapeutic Chemical (ATC) classification system version 2018 (World Health Organization [WHO] 2018). We had information on ATC code and month of dispensing. For the general population we had information on number of users of the relevant ATC codes in 2016 in 1-year age groups for boys and girls.

Sleep medication was defined as melatonin (ATC N05CH), alimemazine/trimeprazine (ATC R06AD01), and benzodiazepines and the z-hypnotics zopiclone and zolpidem (BZD/Z-HYP's; ATC N05CD02, N05CF). Concomitant medication for the following classes of psychotropic medications were studied: antidepressants (ATC N06A), anxiolytics (ATC N05B), antipsychotics (ATC N05A, except N05AN01 [lithium]), and psychostimulants (ATC N06BA). Concomitant medication was defined as at least one prescription of sleep medication during 2016 and at least one prescription of the relevant psychotropic medication classes during 2016.

\section{Statistics}

We compared the prevalence of prescribed sleep medication and concomitant psychotropic medication in $\mathrm{RC}$ with the age- and gender-corrected prevalence in the general child population (GenPop). We also compared boys and girls within and between the two populations. Mean values, percentages, and prevalence ratios (PRs) with $95 \%$ confidence intervals (CIs) are presented. $\mathrm{PR}=\left(n_{1} /\right.$ $\left.N_{1}\right) /\left(n_{2} / N_{2}\right)$, where $n$ and $N$ denote number of users and number of individuals, respectively, in the two populations. Age and gender correction was carried out using the ageadjust.direct function in the 
Girls, N=205

Melatonin, N=115 Alimemazine, N=103

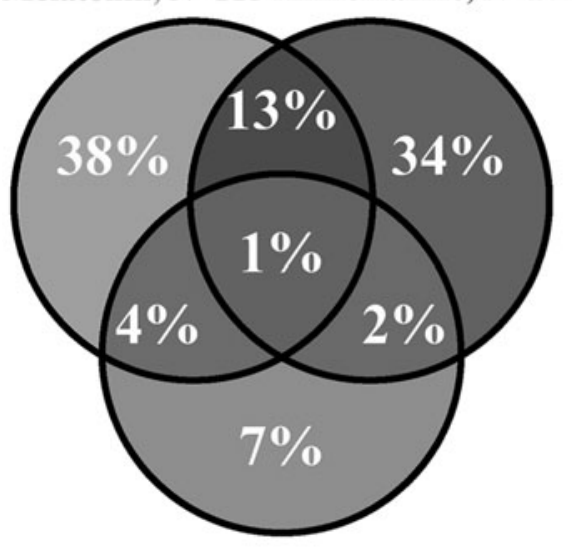

BZD/Z-HYP, N=31
Boys, $\mathrm{N}=166$

Melatonin, $\mathrm{N}=\mathbf{1 2 2}$ Alimemazine, $\mathbf{N}=\mathbf{5 8}$

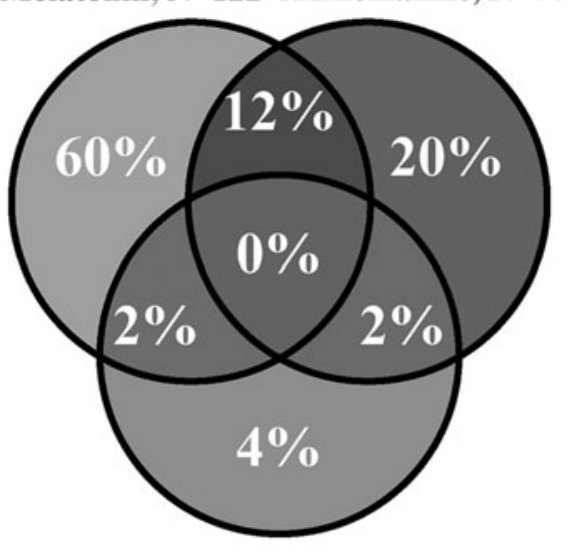

BZD/Z-HYP, N=13

FIG. 1. The use of different sleep medications and their overlaps among girls and boys in residential care.

R-package epitools, with the study population as reference population (1-year age groups). PRs between girls and boys and between $\mathrm{RC}$ and GenPop, with $95 \%$ CIs were computed using the riskscoreci function in the PropCIs package in $\mathrm{R}$ ( $\mathrm{R}$ Development Core Team 2017). When the numerator and/or the denominator of the PR was age and gender corrected, the uncertainty involved in the age and gender correction was taken into account by using a simulation approach (Supplementary Appendix SA2).

\section{Ethics}

The study was approved by The Regional Committee for Medical Research Ethics in South-Eastern Norway (REK), Norwegian Centre for Research Data and the Norwegian Data Inspectorate without informed consent under given conditions. These conditions included data only being handled by one of the authors (V.H.) on a secure server and destroying the linking key to ensure no possibility for back identification of individuals. Furthermore, data were available in 1-year age groups, but are presented in larger intervals (0-5, 6-12 years, etc.) to ensure anonymity. A personal identification number provided by BUFDIR allowed a linkage through the Norwegian National Register to the NorPD prescription data (reference: REK 2017/1637).

\section{Results}

A total of 2171 youths, $40 \%$ girls, were identified in RC at mean age 14 years $(82 \% \geq 13$ years). Among these, $17 \%$ (95\% CI $=15.6-$ 18.7) used sleep medication compared with $2.3 \%$ use in GenPop.

Among those who used sleep medication in RC, 64\% used melatonin, significantly less than the $74 \%$ in GenPop (PR RC/GenPop $[P R]=0.86$; 95\% CI $=0.77-0.94)$. Furthermore, 43\% used alimemazine, significantly more than the $27 \%$ in GenPop ( $P R=1.6 ; 95 \%$ $\mathrm{CI}=1.4-1.9)$, and $12 \%$ used BZD/Z-HYP's, not significantly different from the $9 \%$ in GenPop ( $\mathrm{PR}=1.3$; 95\% CI=0.9-1.8).

In RC, $23 \%$ of the girls used sleep medications compared with $13 \%$ among boys. The girl/boy ratio for medication use in RC was 1.8 (95\% CI $=1.5-2.2$ ), not significantly different from the corresponding ratio in GenPop ( $\mathrm{PR}=1.4 ; 95 \% \mathrm{CI}=1.3-1.5)$. The girl/boy $\mathrm{PRs}$ for the different sleep medications were similar in the two populations (RC and GenPop, nonsignificant data not shown). See Figure 1 for the use of different sleep medications showing that boys used more melatonin, whereas girls used more alimemazine (melatonin/alimemazine ratios were $2.1[95 \% \mathrm{CI}=1.7-2.7]$ and $1.1[95 \% \mathrm{CI}=0.9-1.3]$, respectively).

The use of sleep medication increased with age in both populations ( $\mathrm{RC}$ and GenPop), and in both genders. For girls 13-16 years of age, the use was particularly high compared with GenPop, see Table 1 for the use of sleep medication for youths in RC, with ratios RC/GenPop for each age group (0-5, 6-12, 13-16, and 17-20 years).

For those placed in $\mathrm{RC}$ owing to being unaccompanied minor asylum seekers, the use of sleep medication was $2 \%$, and none used concomitant psychotropic medication. Their use of sleep medication was equivalent to the use in GenPop $(2.2 \%$; $95 \% \mathrm{CI}=1.1-$ $4.5 \%$ ), and significantly lower than for those placed in $\mathrm{RC}$ for other

Table 1. Use of Sleep Medication in Different Age Groups for Youths in Residential Care with Prevalence Ratios (RC/GenPop) and 95\% CONFIDENCE INTERVALS

\begin{tabular}{lrcc}
\hline \multicolumn{1}{c}{ Age, years } & RC $\%$ & GenPop $\%$ & $\begin{array}{c}\text { Ratio RC/GenPop } \\
(95 \% \text { CI })\end{array}$ \\
\hline All & & & \\
$0-5$ & 1.7 & 0.6 & $2.9(1.1-7.7)$ \\
$6-12$ & 7.0 & 1.6 & $4.4(2.3-8.0)$ \\
$13-16$ & 17.1 & 2.2 & $7.7(6.5-9.0)$ \\
$17-20$ & 23.9 & 3.2 & $7.5(6.4-8.7)$ \\
Girls & & & \\
$0-5$ & 2.6 & 0.5 & $5.0(1.6-15.5)$ \\
$6-12$ & 5.0 & 1.0 & $4.9(1.3-17.1)$ \\
$13-16$ & 24.7 & 2.5 & $10.0(8.0-12.5)$ \\
$17-20$ & 31.0 & 4.2 & $7.4(6.1-9.0)$ \\
Boys & & & \\
$0-5$ & 0.8 & 0.6 & $1.3(0.2-7.4)$ \\
$6-12$ & 7.8 & 1.8 & $4.3(2.1-8.3)$ \\
$13-16$ & 12.8 & 2.1 & $6.1(4.8-7.8)$ \\
$17-20$ & 17.8 & 2.4 & $7.5(5.8-9.6)$ \\
\hline
\end{tabular}

CI, confidence interval; GenPop, general child population; RC, residential care. 


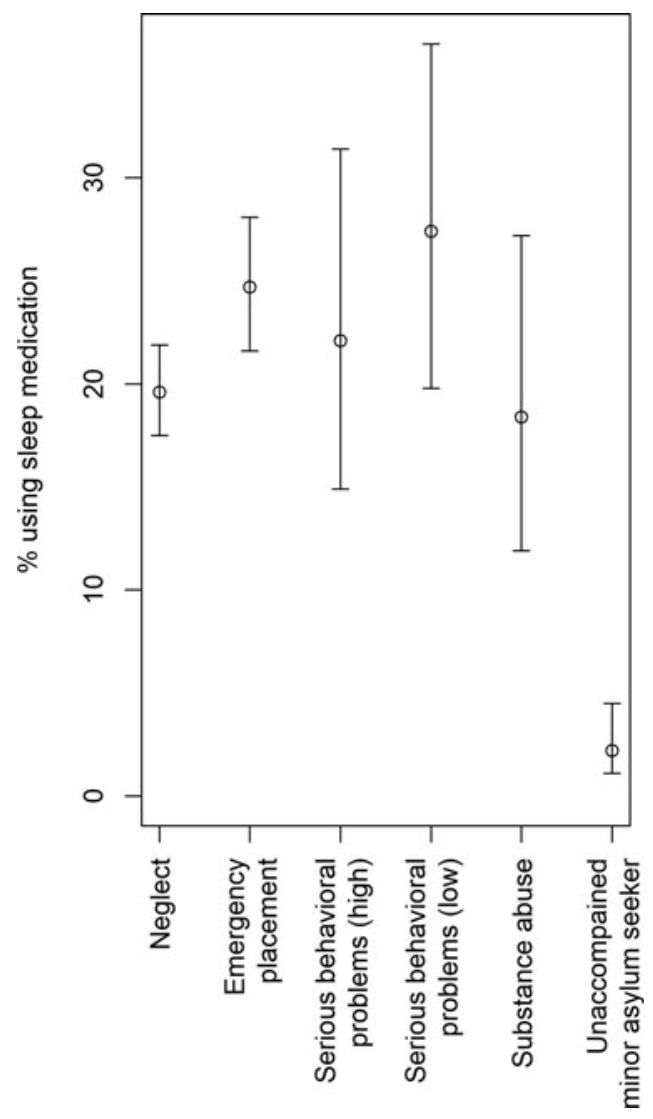

FIG. 2. The use of sleep medication related to the different placement reasons in residential care (mean percentages with $95 \%$ confidence intervals).

reasons, mean $19.6 \%(95 \% \mathrm{CI}=17.9-21.5)$. Figure 2 presents the use of sleep medication related to the different placement reasons.

When comparing all youths who used sleep medication in $\mathrm{RC}$ versus GenPop, the use of concomitant psychotropic medication was significantly more frequent in RC for all classes, apart from psychostimulants, where the ratio RC/GenPop was 0.9 (95\% CI: 0.7-1.2) (Table 2).

About half of the youths in RC who used sleep medication did not use other psychotropic medications ( $45 \%$ of the girls, $51 \%$ of the boys). Approximately, another one-third used one concomitant psychotropic medication ( $30 \%$ of the girls, $35 \%$ of the boys). The use of two concomitant medications was found in $20 \%$ of the girls and $10 \%$ of the boys. Finally, three were the maximum number of concomitant medications used, in 5\% of girls, and $4 \%$ of boys.

When comparing sleep medicated girls and boys in RC, there were evident differences in the use of concomitant medication. Girls used about twice as frequently antidepressants, anxiolytics, and antipsychotics as boys ( $\mathrm{girl} /$ boy $\mathrm{PRs}=2.3,95 \% \mathrm{CI}=1.5-3.5$; $2.7,95 \% \mathrm{CI}=1.3-5.8$; and $1.7,95 \% \mathrm{CI}=1.2-2.5$, respectively), and less psychostimulants (girl/boy $\mathrm{PR}=0.4,95 \% \mathrm{CI}=0.2-0.6$ ).

When investigating girls and boys on sleep medication in the two populations separately, girls on sleep medication in $\mathrm{RC}$ received more of all classes of psychotropic medications (range of PRs were 1.9$3.5)$ apart from psychostimulants $(P R=0.6)$ compared with girls in GenPop (Table 2). For boys on sleep medication in RC, less treatment was found for antidepressants and anxiolytics compared with boys in GenPop (PRs were 0.7 and 0.8), and more treatment with antipsychotics and psychostimulants than boys in GenPop (Table 2).
Table 2. Concomitant Psychotropic Medication in Youths in Residential Care Who Use SLeEP Medication

\begin{tabular}{lrcc}
\hline Drug classes & RC $\%$ & GenPop $\%$ & $\begin{array}{c}\text { Ratio RC/GenPop } \\
(95 \% \text { CI })\end{array}$ \\
\hline All & & & \\
$\quad$ Antidepressants & 23 & 19 & $1.3(1.0-1.6)$ \\
$\quad$ Anxiolytics & 9 & 6 & $1.6(1.1-2.4)$ \\
Antipsychotics & 25 & 10 & $2.6(2.0-3.2)$ \\
$\quad$ Psychostimulants & 19 & 21 & $0.9(0.7-1.2)$ \\
Girls & & & \\
Antidepressants & 31 & 17 & $1.9(1.4-2.4)$ \\
Anxiolytics & 13 & 5 & $2.5(1.6-3.9)$ \\
Antipsychotics & 31 & 9 & $3.5(2.6-4.5)$ \\
$\quad$ Psychostimulants & 11 & 18 & $0.6(0.4-0.9)$ \\
Boys & & & \\
$\quad$ Antidepressants & 14 & 21 & $0.7(0.4-1.0)$ \\
Anxiolytics & 5 & 6 & $0.8(0.4-1.6)$ \\
Antipsychotics & 18 & 11 & $1.6(1.1-2.3)$ \\
Psychostimulants & 30 & 24 & $1.3(0.9-1.6)$ \\
\hline
\end{tabular}

Percentages with prevalence ratios RC/GenPop and 95\% CIs.

$\mathrm{CI}$, confidence interval; GenPop, general child population; RC residential care.

\section{Discussion}

This study compared the use of sleep medication in general, and their combination with concomitant psychotropic medication, among youths placed in RC institutions with the age- and gendercorrected general population (GenPop).

Nearly one in five youths in RC (17\%) used sleep medication, significantly more than the GenPop $(2.3 \%)$, probably resulting from the increased psychosocial strain and mental disorders reported in this population (Ford et al. 2007; Jozefiak et al. 2016). The sleep medications used were mostly melatonin (64\%) and the antihistamine alimemazine (43\%), consistent with surveys on pharmacological management of child insomnia (Owens et al. 2010; Heussler et al. 2013). Fewer youths (12\%) used benzodiazepines/z-hypnotics with potential risk of dependence. It may be positive that the most commonly prescribed drug was melatonin, for two reasons. (1) The effect of melatonin is well documented in children, especially for sleep problems co-occurring with neurodevelopmental disorders (Bruni et al. 2018; McDonagh et al. 2019). (2) Neurodevelopmental disorders were found to be highly prevalent in a recent representative study of youths in Norwegian RC institutions (Autism spectrum disorders: 24\% and ADHD: 33\%) (Jozefiak et al. 2016).

In addition, the fact that boys used more melatonin relative to alimemazine compared with girls, may support that melatonin was prescribed particularly to youths with neurodevelopmental disorders, as these disorders are known to be more prevalent in boys (Suren et al. 2012). For antihistamines, there is lack of randomized controlled trials, but 1 study of 22 children with night awakenings found that alimemazine gave moderate improvement of sleep (France et al. 1999). In addition, the sedating effect has long been recognized (Yanai et al. 1992), and may explain the frequent use in this study.

The use of sleep medication increased with age in both populations, perhaps suggesting that the lack of pharmacological guidelines restrain clinicians in medicating younger children for sleep problems. The particular rise in the use of sleep medication in girls after puberty could result from several factors. A large study investigating gender differences in children 5-12 years of age 
$(n=700)$ reported that the prevalence of insomnia symptoms in girls peaked around age 12 (Calhoun et al. 2014). This increase was associated with objective sleep disturbances, not symptoms of anxiety and depression, and the authors therefore suggested that the increase may be related to hormonal changes in girls associated with the onset of puberty. In addition, the fact that girls in puberty used particularly more sleep medication relative to the girls in GenPop, leaves us to speculate whether being in RC could be a particular strain for girls this age. The significantly lower use of sleep medication among the unaccompanied minor asylum seekers in $\mathrm{RC}(2 \%)$ compared with the rest of the youths placed in $\mathrm{RC}$ for other reasons (17\%) could point to an overlooked subgroup in RC. This is in line with a systematic literature review, demonstrating a general underutilization of mental health services by refugee children (Colucci et al. 2014), and a recent Norwegian review (Debesay et al. 2019). This is despite the fact that the prevalence of mental health problems is known to be higher than in host populations (Fazel et al. 2005; Fazel 2018).

This study found that the use of concomitant antidepressants (selective serotonin reuptake inhibitors [SSRIs]), anxiolytics, and antipsychotics were significantly higher among the sleepmedicated children and adolescents in RC compared with the sleep medicated in GenPop. About 23\% among the sleep medicated in RC, also used SSRIs (1.3 times more than in GenPop [95\% $\mathrm{CI}=1.1-1.5]$ ), medications usually prescribed to treat depression and/or anxiety disorders. As SSRIs can promote wakefulness (Krystal et al. 2013), these may detract from the sleep-promoting effects of the sleep medications. None of the children and adolescents in RC used tricyclic antidepressants known to promote sleep (Krystal et al. 2013), and may result from clinicians' awareness of the marginal evidence to support the use of tricyclic drugs in the treatment of depression in adolescents (Hazell and Mirzaie 2013).

Approximately $25 \%$ among the sleep medicated in RC used antipsychotics, about 2.6 times more than in GenPop (ratio RC/Gen$\mathrm{Pop}=2.6[95 \% \mathrm{CI}=2.1-3.0]$ ). This was not unexpected, as sedating antipsychotics (such as quetiapine, risperidone, and olanzepine) approved for schizophrenia and bipolar disorder, is effective at lower doses for insomnia (Asnis et al. 2015). Owing to side effects, however, antipsychotics are not recommended to improve sleep (Asnis et al. 2015). Although we cannot know with certainty, the clinicians may also have considered the effect some antipsychotics may have on calming agitation and/or disruptive behavior (Loy et al. 2017), as it is unlikely that as many as $1 / 5$ of the sleep medicated in RC has psychosis or bipolar disorder. The clinicians may also have weighed the additional sleep-promoting effect as positive. That the antipsychotics used by the participants of this study may in part have been prescribed to reduce disruptive behavior is supported by that $>20 \%$ of the sleep medicated in $\mathrm{RC}$ were registered with "serious behavioral problems" as reasons for placement.

In this study, about half of the youths in RC who used sleep medication did not use other psychotropic medications, and the maximum number of concomitant medications used was three, in $5 \%$ of girls, and $4 \%$ of boys. This is considerably lower than occurrence rates reported in a U.S. study of children in foster care, where $41 \%$ were prescribed three or more psychotropic medications (Zito et al. 2008b). In line with known epidemiological patterns for antidepressants and psychostimulants in the general youth population (Sultan et al. 2018), we found that girls in RC used more medication indicated for anxiety and depression, whereas boys used more psychostimulants, for which ADHD is the main indication. However, our findings could suggest an undertreatment with psychostimulants for girls in $\mathrm{RC}$, in line with a study showing that girls with ADHD were less likely to receive medication, unless they also had prominent disruptive symptoms (Mowlem et al. 2019).

\section{Strengths and limitations}

A strength of this study is the use of a national prescription registry, which includes all patients treated with sleep medication and psychotropic medication in Norway. As such, it provides valuable information about the filled prescription/dispensed medication in this cohort of youths in RC and may be considered representative of clinical practice.

Our study had several limitations. First, although we have valid data on dispensed medication, and thus, primary nonadherence is not an issue, we have no knowledge of whether the child actually took the medication. Second, the NorPD only provides data for filled prescriptions. Thus, because diagnostic information was not available, we cannot report on the indications for prescription or the prevalence of psychiatric disorders. Third, "concomitant" psychotropic medication indicates that they are used during 2016, not necessarily at the exact same time as sleep medications. However, this pertains to both populations and the comparison with the general population is therefore fair. Finally, we do not know whether the participants were adequately assessed for specific sleep disorders or offered recommended behavioral interventions for sleep problems before medication was prescribed.

\section{Conclusions}

In this representative population of youths in RC, approximately one in five used sleep medication, and the percentage of concomitant medication could point to a high prevalence of psychiatric disorders in RC youths medicated for sleep problems. However, given the high prevalence of psychiatric disorders previously reported in RC populations, the present findings do not necessarily indicate an overtreatment with medication in RC.

However, the literature has underlined that children with sleep problems are generally not adequately assessed and treated, and to which extent this also applies to the vulnerable youths in RC, needs to be investigated.

\section{Clinical Significance}

Clinicians should be aware of that a large proportion of youths in $\mathrm{RC}$ may have sleep problems.

\section{Author Note}

This study was conducted at Innlandet Hospital Trust.

\section{Acknowledgments}

We thank librarian Ellen Bjoernstad, Oslo University Hospital, for the literature searches.

\section{Disclosures}

No competing financial interests exist.

\section{Supplementary Material}

Supplementary Appendix SA1

Supplementary Appendix SA2

\section{References}

Alfano CA, Gamble AL: The role of sleep in childhood psychiatric disorders. Child Youth Care Forum 38:327-340, 2009. 
Asnis GM, Thomas M, Henderson MA: Pharmacotherapy treatment options for insomnia: A primer for clinicians. Int J Mol Sci 17, 2015.

Baddam SKR, Canapari CA, van Noordt SJR, Crowley MJ: Sleep disturbances in child and adolescent mental health disorders: A review of the variability of objective sleep markers. Med Sci (Basel) 6:pii: E46, 2018.

Bruni O, Angriman M, Calisti F, Comandini A, Esposito G, Cortese S, Ferri R: Practitioner review: Treatment of chronic insomnia in children and adolescents with neurodevelopmental disabilities. J Child Psychol Psychiatry 59:489-508, 2018.

Bruni O, Angriman M, Melegari MG, Ferri R: Pharmacotherapeutic management of sleep disorders in children with neurodevelopmental disorders. Expert Opin Pharmacother 20:2257-2271, 2019.

Calhoun SL, Fernandez-Mendoza J, Vgontzas AN, Liao D, Bixler EO: Prevalence of insomnia symptoms in a general population sample of young children and preadolescents: Gender effects. Sleep Med 15:91-95, 2014.

Colucci E, Szwarc J, Minas H, Paxton G, Guerra C: The utilisation of mental health services by children and young people from a refugee background: A systematic literature review. Int J Cult Ment Health 7:86-108, 2014.

Debesay J, Arora S, Bergland A: Migrants' consumption of Healthcare Services in Norway: Inclusionary and exclusionary structures and practices. In: Inclusive Consumption Immigrants'Access to and Use of Public and Private Goods and Services. Edited by Borch A, Harslof I, Klepp IG, Laitala K. Oslo, Universitetsforlaget, 2019, pp. 63-78.

Economou NT, Ferini-Strambi L, Steiropoulos P: Sleep-related drug therapy in special conditions: Children. Sleep Med Clin 13:251262, 2018.

Fazel M: Psychological and psychosocial interventions for refugee children resettled in high-income countries. Epidemiol Psychiatr Sci 27:117-123, 2018.

Fazel M, Wheeler J, Danesh J: Prevalence of serious mental disorder in 7000 refugees resettled in western countries: A systematic review. Lancet 365:1309-1314, 2005.

Ford T, Vostanis P, Meltzer H, Goodman R: Psychiatric disorder among British children looked after by local authorities: Comparison with children living in private households. Br J Psychiatry 190: 319-325, 2007.

France KG, Blampied NM, Wilkinson P: A multiple-baseline, doubleblind evaluation of the effects of trimeprazine tartrate on infant sleep disturbance. Exp Clin Psychopharmacol 7:502-513, 1999.

Garland AF, Hough RL, McCabe KM, Yeh MAY, Wood PA, Aarons GA: Prevalence of psychiatric disorders in youths across five sectors of care. J Am Acad Child Adolesc Psychiatry 40:409-418, 2001.

Green JG, McLaughlin KA, Berglund PA, Gruber MJ, Sampson NA, Zaslavsky AM, Kessler RC: Childhood adversities and adult psychiatric disorders in the National Comorbidity Survey Replication I: Associations with first onset of DSM-IV Disorders National Comorbidity Survey Replication I. Arch Gen Psychiatry 67:113123, 2010.

Hambrick EP, Rubens SL, Brawner TW, Taussig HN: Do sleep problems mediate the link between adverse childhood experiences and delinquency in preadolescent children in foster care? J Child Psychol Psychiatry 59:140-149, 2018.

Hartz I, Furu K, Bratlid T, Handal M, Skurtveit S: Hypnotic drug use among 0-17 year olds during 2004-2011: A nationwide prescription database study. Scand J Public Health 40:704-711, 2012.

Hazell P, Mirzaie M: Tricyclic drugs for depression in children and adolescents. The Cochrane Database Syst Rev CD002317, 2013.

Heussler H, Chan P, Price AM, Waters K, Davey MJ, Hiscock H: Pharmacological and non-pharmacological management of sleep disturbance in children: An Australian Paediatric Research Network survey. Sleep Med 14:189-194, 2013.

Johnson EO, Roth T, Schultz L, Breslau N: Epidemiology of DSM-IV insomnia in adolescence: Lifetime prevalence, chronicity, and an emergent gender difference. Pediatrics 117:e247-e256, 2006.

Jozefiak T, Kayed NS, Rimehaug T, Wormdal AK, Brubakk AM, Wichstrom L: Prevalence and comorbidity of mental disorders among adolescents living in residential youth care. Eur Child Adolesc Psychiatry 25:33-47, 2016.

Krystal AD, Richelson E, Roth T: Review of the histamine system and the clinical effects of $\mathrm{H} 1$ antagonists: Basis for a new model for understanding the effects of insomnia medications. Sleep Med Rev 17:263-272, 2013.

Kutz GD: Foster children: HHS guidance could help states improve oversight of psychotropic prescriptions. Gen Account Off Report GAO-12-270T 2011.

Langevin R, Hebert M, Bergeron SJ, Duchesne M, Lambert Y, Chartrand R, Frappier JY: Sleep problems and interpersonal violence in youth in care under the Quebec Child Welfare Society. Sleep Med 56:52-56, 2019.

Lehmann S, Havik OE, Havik T, Heiervang ER: Mental disorders in foster children: A study of prevalence, comorbidity and risk factors. Child Adolesc Psychiatry Ment Health 7:39, 2013.

Leslie LK, Raghavan R, Zhang J, Aarons GA: Rates of psychotropic medication use over time among youth in child welfare/child protective services. J Child Adolesc Psychopharmacol 20:135-143, 2010.

Lopez-Leon S, Lopez-Gomez MI, Warner B, Ruiter-Lopez L: Psychotropic medication in children and adolescents in the United States in the year 2004 vs 2014. DARU J Pharm Sci 26:5-10, 2018.

Loy JH, Merry SN, Hetrick SE, Stasiak K: Atypical antipsychotics for disruptive behaviour disorders in children and youths. Cochrane Database Syst Rev 8:CD008559, 2017.

Maski K, Owens J: Pediatric sleep disorders. Continuum (Minneap Minn) 24:210-227, 2018.

McDonagh MS, Holmes R, Hsu F: Pharmacologic treatments for sleep disorders in children: A systematic review. J Child Neurol 34:237247, 2019.

Meltzer LJ, Plaufcan MR, Thomas JH, Mindell JA: Sleep problems and sleep disorders in pediatric primary care: Treatment recommendations, persistence, and health care utilization. J Clin Sleep Med 10:421-426, 2014.

Mowlem FD, Rosenqvist MA, Martin J, Lichtenstein P, Asherson P, Larsson H: Sex differences in predicting ADHD clinical diagnosis and pharmacological treatment. Eur Child Adolesc Psychiatry 28: 481-489, 2019.

Owens JA, Moturi S: Pharmacologic treatment of pediatric insomnia. Child Adolesc Psychiatr Clin N Am 18:1001-1016, 2009.

Owens JA, Rosen CL, Mindell JA, Kirchner HL: Use of pharmacotherapy for insomnia in child psychiatry practice: A national survey. Sleep Med 11:692-700, 2010.

Pelayo R, Yuen K: Pediatric sleep pharmacology. Child Adolesc Psychiatr Clin N Am 21:861-883, 2012.

R Development Core Team R: A Language and Environment for Statistical Computing. R Foundation for Statistical Computing, Vienna, Austria, 2017.

Ramtekkar U, Ivanenko A: Sleep in children with psychiatric disorders. Semin Pediatr Neurol 22:148-155, 2015.

Rubin D, Matone M, Huang Y-S, dosReis S, Feudtner C, Localio R: Interstate variation in trends of psychotropic medication use among Medicaid-enrolled children in foster care. Child Youth Serv Rev 34:1492-1499, 2012.

Schroder C, Dorks M, Kollhorst B, Blenk T, Dittmann RW, Garbe E, Riedel O: Outpatient antidepressant drug use in children and ado- 
lescents in Germany between 2004 and 2011. Pharmacoepidemiol Drug Saf 26:170-179, 2017.

Sivertsen B, Harvey AG, Pallesen S, Hysing M: Trajectories of sleep problems from childhood to adolescence: A population-based longitudinal study from Norway. J Sleep Res 26:55-63, 2017.

Stojanovski SD, Rasu RS, Balkrishnan R, Nahata MC: Trends in medication prescribing for pediatric sleep difficulties in US outpatient settings. Sleep 30:1013-1017, 2007.

Sultan RS, Correll CU, Schoenbaum M, King M, Walkup JT, Olfson M: National patterns of commonly prescribed psychotropic medications to young people. J Child Adolesc Psychopharmacol 28:158$165,2018$.

Suren P, Bakken IJ, Aase H, Chin R, Gunnes N, Lie KK, Magnus P, Reichborn-Kjennerud T, Schjølberg S, Øyen AS, Stoltenberg C: Autism spectrum disorder, ADHD, epilepsy, and cerebral palsy in Norwegian children. Pediatrics 130:e152-e158, 2012.

Turney K, Wildeman C: Mental and physical health of children in foster care. Pediatrics 138, 2016.

Warner LA, Song NK, Pottick KJ: Outpatient psychotropic medication use in the US: A comparison based on foster care status. J Child Fam Stud 23:652-665, 2014.

World Health Organization (WHO): CCfDSM ATC Classification Index with DDDs, 2018. Oslo: Centre for Drug Statistics and Methodology; 2018.
Yanai K, Watanabe T, Yokoyama H, Meguro K, Hatazawa J, Itoh M, Iwata R, Ishiwata K, Takahashi T, Ido T: Histamine H1 receptors in human brain visualized in vivo by $[11 \mathrm{C}]$ doxepin and positron emission tomography. Neurosci Lett 137:145-148, 1992.

Zito JM, Safer DJ, de Jong-van den Berg LT, Janhsen K, Fegert JM, Gardner JF, Glaeske G, Valluri SC: A three-country comparison of psychotropic medication prevalence in youth. Child Adolesc Psychiatry Ment Health 2:26, 2008a.

Zito JM, Safer DJ, Sai D, Gardner JF, Thomas D, Coombes P, Dubowski M, Mendez-Lewis M: Psychotropic medication patterns among youth in foster care. Pediatrics 121:e157-e163, 2008 b.

Address correspondence to: Beate Oerbeck, $P h D$ Division of Mental Health and Addiction Oslo University Hospital Pb. 4959 Nydalen 0424 Oslo Norway

E-mail: b-oerbe@online.no 